\title{
A STEPWISE ISO-BASED TQM IMPLEMENTATION APPROACH USING ISO 9001:2015
}

\author{
Chi-kuang Chen ${ }^{1}$, Karina Anchecta ${ }^{1}$, Yuan-Duen Lee ${ }^{2}$, Jens J. Dahlgaard ${ }^{3}$ \\ ${ }^{1}$ Department of Industrial Engineering and Management, Yuan Ze University, Taiwan \\ ${ }^{2}$ Department of Business and Operations Management, Chang Jung Christian University, Taiwan \\ ${ }^{3}$ Department of Management and Engineering, Linkoping University, Sweden
}

Corresponding author:

Chi-kuang Chen

Department of Industrial Engineering and Management

Yuan Ze University

135 Yuan-Tung Road, Chung-Li, Tao-Yuan, Taiwan 32003, R.O.C.

phone: $(+886)$ 3-4638800 ext: 2528

e-mail: ieckchen@saturn.yzu.edu.tw

Received: 16 March 2016

Accepted: 28 July 2016

\begin{abstract}
The lack of an implementation roadmap always deters enterprises from choosing Total Quality Management (TQM) as its major management approach. This paper proposes a stepwise ISO-based TQM implementation approach which is based on the notion of the new threedimensional overall business excellence framework developed by Dahlgaard et al. [1]. The proposed approach consists of nine steps comprising three categories: "TQM faith building", "TQM tools and techniques learning", and "system development". The steps in each of the three categories are arranged to span across the proposed nine-step approach. The ISO 9001:2015 standard is used as a case study to demonstrate the proposed approach. The ideas and benefits of the proposed approach are further discussed in relation to this illustration. Total Quality Management, TQM, ISO QMS, ISO 9000, ISO 9001:2015.
\end{abstract}

\section{Introduction}

Total Quality Management (TQM) and the ISObased Quality Management System (QMS) have been two of the most popular approaches chosen by enterprises to build their QMSs since the 1980s. TQM is presented as a holistic approach, which engenders customer orientation, employee and customer empowerment, attention to processes, a wellfunctioning QMS, and continuous improvement [2, 3]. It is essentially a way of organizing and ensuring the participation of the entire company, specifically every department, every activity, and every single employee at all levels of the organization. The ISO-based QMS is based on the same quality management principles. It provides guidance to companies that want to ensure that their products/services consistently meet customers' requirements and that their product/service quality undergoes continual improvements.

For an organization to be truly effective in implementing TQM, each component must work together in harmony, recognizing that every person and every activity affects, and is in turn, affected, by others. For this reason, any organization with an ISO-certified QMS is required to conduct internal audits, to check the health of its QMS and ensure that it can satisfy customer requirements.

However, empirical evidence shows that both approaches are difficult to implement, and sometimes, they even conflict with each other [4]. For example, the ISO-based QMS might become too rigid and has been mainly used just to meet requirements. In fact, it is well known that the implementation methods adopted by many organizations are only directed toward attaining ISO certification. TQM, on the other hand, is often believed to suffer from the lack of a clear implementation roadmap to be followed by practitioners [5-7]. However, TQM and the ISObased QMS are both recognized as focusing on management and leadership, commitment and involvement, prevention and detection of errors and defects, customer focus, and effective implementation. Thus, combining the positive aspects of the two approaches can be beneficial, provided it is possible to strengthen the systems and procedures of both approaches and 
convert the same into an integrated system. Doing so can lead to better results, especially because the ISO-based QMS might be a good beginning for TQM implementation; the QMS is considered by many to be a stepping stone towards TQM $[8,9]$.

Accordingly, the main purpose of this study is to develop an ISO-based TQM implementation approach by using the three-dimensional overall business excellence framework proposed by Dahlgaard et al. [1]. The proposed approach consists of a ninestep implementation approach covering three categories that are specifically arranged to overlap among themselves.

\section{Literature review}

\section{Total quality management}

TQM refers to a management philosophy including tools and methods used to enhance quality and productivity in organizations. The basic principles of TQM are intended to achieve continuous organizational improvement through the participation and commitment of all its employees. TQM focuses on ensuring that all the resources of an organization are employed strategically toward meeting the needs of its customers (both internal and external), using statistical tools and techniques to measure results and aid decision making. The basic philosophy of TQM is trying to "Doing the right thing right first time, on time, all the time, always striving for improvement, and always satisfying the customers". It involves all the departments and employees, focusing on continuous process improvement within the organization, so as to provide superior customer value and meet or exceed customer expectations.

Gharakhani et al. [10] stated that TQM helps the organization achieve and maintain success over the long term. However, the approach seems to have lost its attractiveness in the last decade, and instead, new terms like Business Excellence, Organizational Excellence, Six Sigma, and Lean Six Sigma seem to have overtaken the position previously occupied by TQM [7]. However, TQM is not only the first management approach to embrace both the western and eastern ways of thinking and practices, but it is also the first comprehensive management approach to cover the three key areas of management: Process/Operation Management, Human Resource Management, and Strategic Management. Hence, TQM can be understood as a motivation, if not a revolution, toward better management [6].

Dahlgaard-Park et al. [11] hold that TQM has become a comprehensive management approach that includes multiple layers and elements/components within its umbrella, and the issues related to its implementation are as below.

1. Does TQM work?

2. If it works, does it work in any situation?

3. What is the best implementation strategy?

4. What are the critical success factors?

5. How do you choose the best roadmap and tools?

\section{ISO-based QMS certification}

The ISO-based QMS is a management standard that presents a sequence of steps intended to increase business efficiency and customer satisfaction, thus helping organizations meet the needs of customers and other stakeholders as well as the regulatory requirements related to their products/services. It is a QMS that has been created to monitor the functions and data of a specific organization, which helps maintain and keep the proper balance within it.

The ISO-based QMS is an internationally recognized standard that can be implemented by any organization, whether small or large; this certification can benefit both marketing and promotional aspects, as well as lead to organizational improvements. Various manufacturing organizations were early adopters of the ISO-based QMS. Lately, this approach has found favor with numerous services-based area associations as well.

ISO 9001 certification became popular among other reasons because an ISO-based QMS, when properly implemented, could help to improve efficiency and hence business competitiveness. In short, the benefits of properly implementing an ISO-based QMS may include:

- Cost savings: helps optimize the organization's operations.

- Enhanced customer satisfaction: helps improve quality, enhance customer satisfaction, and increase sales.

- Access to new markets: assists in overcoming trade barriers and opening up global markets.

- Increased market share: helps increase productivity and competitive advantage.

- Environmental benefits: aids in reducing negative impacts on the environment.

Various organizations earned this certification for their business operations because as increasingly more of their suppliers became ISO 9001-compliant, they also requested the organization to attain the certification as well. One of the main results for many companies in implementing this approach is improved sales; many companies experienced that 
without having attained the ISO 9001 certification they could not have won a significant number of new contracts.

The literature also shows, however, that the certified companies do not really focus on building an efficient and effective framework that would allow them to reap all the benefits of an ISO 9001 certification. The problems experienced from many companies are among other things that maintaining ISO 9001 certification is perceived to be time consuming, bureaucratic and too costly [12].

\section{Linkage between TQM and the ISO-based approach}

Regarding the relationship between ISO 9001 implementation and its subsequent evolution to the adoption of TQM, many experts argue that in order to achieve more benefits, the organization's first step should be to attain certification. Research has demonstrated that companies certified as ISO 9001compliant practice higher levels of TQM than their uncertified counterparts. However, recent studies for countries like Singapore have not been able to provide similar evidence [4]. The reason for that may be that some of the elements of the ISO standard could be contrary to that of a TQM based management system, such as lack of flexibility and the considerable number of controls required for ISO 9001 implementation.

Regarding the impacts of implementing a TQM based management system, research have also shown different results. The early research by Black and Lynch [5] found that the use of TQM did not seem to have any impact on organizational productivity but the comprehensive research by Hendrics \& Singhal [15] and Boulter, Bendell \& Dahlgaard [13] showed quite opposite results.

Why these different results? We believe that when companies fail with TQM implementation the main reason is that they do not respect several of the basic TQM principles during the implementation phase. For example people - managers as well as ordinary employees - do not get enough education and hence they are not respected enough during the critical implementation process, just commanded to do things differently without understanding why. Of course such an implementation approach will lead to failure, and no positive impacts can be shown after implementation because the implemented management system is not really based on the TQM basic principles.

A root cause of the many TQM implementation failures may be that TQM for many reasons lacks an overall implementation strategy to control the tim- ing and tasks of the various practices that need to be implemented as part of the system.

This study advocates building a stepwise learning strategy based on the ISO approach to educate employees on the important principles and aspects of TQM. The logic behind this reasoning lies in the notion that TQM is an improvement to the ISO-based approach which helps the organization to develop, produce and deliver quality products and services in a consistent manner which will satisfy its customers; conversely, attaining the ISO certification is no guarantee for providing high quality products and services. The ISO-based approach focuses on the establishment of a quality system. TQM focuses not only on the establishment of a quality system but also on the realization of continuous improvement in quality. Therefore combining the two methods can help any organization to meet customer requirements consistently and efficiently.

\section{Development of the proposed approach}

\section{The framework}

The purpose of this research is to develop an ISObased stepwise TQM implementation approach that can be used as a tool to help organizations achieve excellence whilst maintaining the basic TQM principles and obtaining the benefits of both ISO and TQM. The notion used to develop the proposed approach is based on the overall business excellence framework of Dahlgaard et al. [1]. The framework has a threedimensional design that complements existing business excellence models, and it helps organizations to integrate appropriate management tools/techniques with suitable organizational culture/characteristics.

The approach proposed here consists of nine TQM implementation steps covering the following three categories: "TQM faith building", "TQM tools and techniques learning", and "ISO-based system development". See Fig. 1.

Figure 1 represents the framework of the nine steps and their interconnections, and Table 1 contains a brief description of the nine-step approach.

The approach begins with "TQM faith building", which refers to the management of the organizational culture and the organizational characteristics that are needed to cultivate a TQM culture among its employees. "TQM tools and techniques learning" determines the best tools and techniques for each department within the organization, so as to assist in planning, operation, and improvement. "ISO system development" serves as quality system guidance towards achieving business excellence and conducting assessments of the organization's performance. 


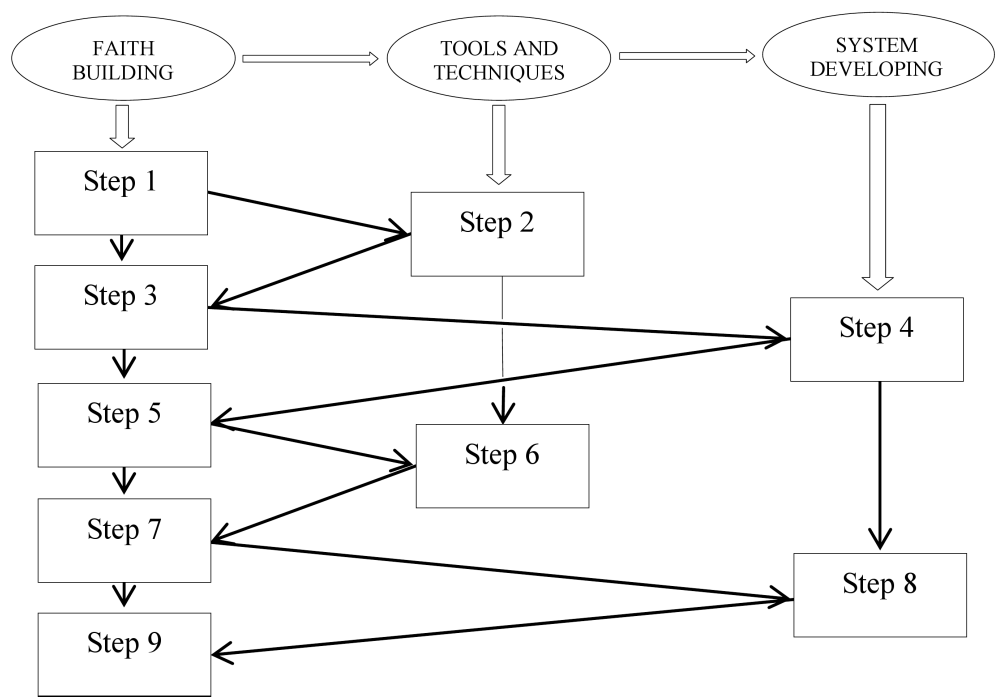

Fig. 1. Framework of the stepwise ISO-based TQM implementation approach.

Table 1

Description of the steps.

\begin{tabular}{c|c|l|l}
\hline Step & \multicolumn{1}{|c|}{ Category } & \multicolumn{1}{|c}{ Description } & \multicolumn{1}{c}{ Method } \\
\hline 1 & TQM faith building-1 & $\begin{array}{l}\text { Building faith in the TQM approach } \\
\text { using the historical examples of role } \\
\text { models/organizations/enterprises. }\end{array}$ & $\begin{array}{l}\text { To look up role models or organizations } \\
\text { from a historical perspective (e.g., Ed- } \\
\text { wards Deming and Joseph Juran). }\end{array}$ \\
\hline 2 & TQM tools/techniques learning-1 & $\begin{array}{l}\text { Learning about TQM tools and } \\
\text { techniques using the educational } \\
\text { tools/techniques relating to quality. }\end{array}$ & $\begin{array}{l}\text { Giving employees proper education } \\
\text { and training, using either direct em- } \\
\text { ployee training or e-learning. }\end{array}$ \\
\hline 3 & TQM faith building-2 & $\begin{array}{l}\text { Building faith in the TQM approach } \\
\text { using the current examples of role } \\
\text { models/organizations/enterprises. }\end{array}$ & $\begin{array}{l}\text { To find and imitate a role model from } \\
\text { the current era; the model should have } \\
\text { demonstrated a good implementation } \\
\text { method (e.g., Jack Welch). }\end{array}$ \\
\hline 5 & ISO system development-1 & $\begin{array}{l}\text { Developing an ISO-based system at } \\
\text { the strategic level. }\end{array}$ & $\begin{array}{l}\text { Developing a strategy before the actual } \\
\text { implementation starts, using clauses 1, } \\
\text { 3, 4, and 6 from ISO 9001. }\end{array}$ \\
\hline 6 & TQM faith building-3 & $\begin{array}{l}\text { Building faith in TQM with the help } \\
\text { of role models within the organiza- } \\
\text { tion. }\end{array}$ & $\begin{array}{l}\text { Studying organizations that have im- } \\
\text { plemented TQM and have had specific } \\
\text { outstanding role models, like Wilbert } \\
\text { James from TOYOTA Corporation. }\end{array}$ \\
\hline 7 & TQols/techniques learning-2 & $\begin{array}{l}\text { Learning about TQM tools and tech- } \\
\text { niques by implementing quality im- } \\
\text { provement projects. }\end{array}$ & $\begin{array}{l}\text { Implementing projects using the TQM } \\
\text { approach and QCC competition to } \\
\text { learn TQM tools and techniques. }\end{array}$ \\
\hline 8 & ISO system development-2 & $\begin{array}{l}\text { Building faith in TQM by devising } \\
\text { quality improvement projects. }\end{array}$ & $\begin{array}{l}\text { Explaining how an organization can } \\
\text { become successful and analyzing their } \\
\text { implementation practices. }\end{array}$ \\
\hline
\end{tabular}

\section{Building faith in TQM}

In order for an organization to prosper in a competitive environment, building faith in TQM is the very first step in establishing a highly functioning or- ganization as a whole. Therefore, it is vital to create a TQM culture throughout the entire organization.

"TQM faith building" refers to the belief in the success that can be derived from personal career development, enterprise, and social sustainability by 
implementing TQM in every organizational activity. Building faith in TQM acts as the change agent necessary for the successful implementation of the approach. The five steps within this category are arranged in a manner that builds faith in TQM alongside employees learning about the history and knowledge pertaining to quality management. They are illustrated in the following paragraphs.

Step-1: TQM faith building-1: Building faith and trust in the TQM approach using historical case studies of role models/organizations/enterprises.

This first step involves conducting research on role models or organizations from a historical perspective. When a role model's version of the transformation story is understood by employees, they appreciate the reasons behind his/her success. This encourages debates on the topic, reinforcing lessons learnt, and prompting employees to infuse the examples with their own personal meanings.

One such example is that of Bell Labs' physicist, Dr. Walter A. Shewhart, who proposed the control chart as a method to determine when a process is in a state of statistical control. Another famous influential leader in quality management is Edwards W. Deming, who is mostly known for his creation of the Plan-Do-Study-Act (Deming) cycle and Deming's 14 points, and his work as an educator in the Japanese industry. His message was "By improving quality companies will decrease expenses as well as increase productivity and market share". Although Deming did not coin the term Total Quality Management he is credited with starting the TQM movement.

Step-3: TQM faith building-2: Building faith in TQM using examples of role models/similar organizations/enterprises in the current era.

The second step with regard to building faith in TQM is to find and imitate a role model from the current era. Role models that may have devised quality management methods are good examples. They could be business leaders as well. Those who aspire to the mantle of leadership will attain insider's knowledge about how other role models succeeded, and therefore created faith by embracing change, setting goals, achieving better performance, considering good ideas for the betterment of the company, and more. For instance, Jack Welch can be considered as a good role model. He is one of the 20th century's most dynamic and successful corporate leaders, and he became one of history's most accomplished CEOs by rewriting the rules of leadership, and letting hands-on frontline employees, instead of bureaucrats, guide him as to the actions that needed to be taken.
Step-5: TQM faith building-3: Building faith in TQM with the help of role models within the organization.

The third step for building faith in TQM concerns emulating role models within the organization. This may be accomplished by learning from employees in organizations that practice TQM successfully. For example, TOYOTA, which has thousands of employees worldwide, has Wilbert W. James as a role model. He was named president of one of TOYOTA's plants, climbing his way to the top after joining the team in 1987 as an assembly group leader. Now, as an organization leader and the first African-American president of TOYOTA Motor Manufacturing, he is a role model for employees across the organization and embodies the spirit that helps strengthen it.

Step-7: TQM faith building-4: Building faith in TQM by devising quality improvement projects.

The fourth step with regard to building faith in TQM involves quality improvement projects. Employees can learn much from implementing such projects. For example, what actions are necessary to make quality improvements? What was their experience like? How have their new and past experiences helped them continue improving? By learning from practical experiences the organization can eventually transform its business strategy and vision and improve its processes for better service delivery and heightened customer satisfaction.

Consider the example of XEROX which decided to integrate Six Sigma and Lean Management as a corporation-wide strategy. To do so, the top management committed the resources required to enable a robust deployment, identified projects based on value creation, and engaged with every function and value chain across the organization. Key deployment management positions were staffed in every major department, and full-time candidates were identified based on the individual's performance record, leadership potential, and training. The leadership at all levels in XEROX worked to integrate Lean Six Sigma principles into all business processes including product design and development, integrated supply chain, marketing and sales, customer services, infrastructure/governance, and strategy deployment. By using this TQM practice, XEROX moved from being a good organization to a truly excellent and successful one.

Step-9: TQM faith building-5: Building faith in TQM by "self-actualizing" quality improvement projects.

The last step regarding building faith in TQM concerns the actual implementation of quality improvement projects wherein each employee recog- 
nizes the methods and processes that can be used to develop the organization's understanding about its own functioning and state of its environment. The "self-actualizing" employee accepts organizational change in line with the changes operating in his/her own environment. This implementation is a strategic way to respond to the new challenges in an environment subjected to change and uncertainty.

Surveys and interviews can be used to acquire information and verify whether the proposed stepwise implementation is successful, why it helped, and how it is believed to have worked.

\section{Learning about TQM tools and techniques}

In order to put all quality tools into practice, first, employees must learn how to apply or use them. "TQM tools and techniques learning" refers to the education, training, and practice of quality management tools/techniques, which are: the Seven Quality Control (QC) tools, Quality Function Deployment (QFD), New QC Tools, TOYOTA Production System/Just-In-Time (TPS/JIT), Total Productive Maintenance (TPM), and Six Sigma. Learning TQM tools and techniques provides all kinds of benefits, including work improvement and increased skills. The explanation for the two steps involved in learning tools and techniques appears below.

Step-2: TQM tools/techniques learning-1: Learning about TQM tools and techniques using the educational tools/techniques relating to quality.

This step is used in order to properly train and educate employees. Some of the most popular tools towards TQM adoption are: flowcharts, histograms, check sheets, scatter diagrams, Pareto analysis, cause and effect diagram and many more. It has to allow employees to learn in different ways, either through direct training or e-learning programs. Direct training provides a foundation for knowledge to grow. E-learning programs could consist of typical course videos explaining how to use the TQM tools and techniques.

Step-6: TQM tools/techniques learning-2: Learning about TQM tools and techniques by implementing quality improvement projects.

This step requires employees to practice what they have learned from step-2. Practicing quality improvement through TQM tools is the fundamental building block for all organizations that wish to achieve process quality improvement. The practice can help transform inputs, including actions, methods, and operations, into quality outputs. Not only do employees gain experience from what they have learned, but employers can also gauge the progress of the employees and the benefits accrued to the organizations' operations as a whole.

\section{Developing the ISO-based system}

System development is necessary as the organization needs to create a framework within which it can implement its quality process.

"ISO system development" refers to the development of an ISO-based system in a strategic and operational manner. The two steps relevant to system development are as follows.

Step-4: ISO system development-1: Developing the ISO-based system at the strategic level.

It is important for an organization to first develop a strategy before operationalizing it. In this regard, the most important document for establishing and implementing an ISO certification system is the quality manual. This manual contains all the information necessary for the oversight, controlling, and designing of the processes needed to ensure the efficiency of business operations. It contains the quality policy statement underlining management's commitment to quality as well as the organization's quality policy and information about responsibilities. The lessons learned from steps 1 and 3, which focus on building the employees' faith in TQM, should have a significant impact on developing a strategic quality system.

Step-8: ISO system development-2: Developing an ISO-based system at the operational level.

The operational level includes the quality procedures, standard operating procedures (SOPs), work instructions, and quality records. The operation level is typically driven by the overall business strategy of the organization and is designed to maximize the effectiveness of production and support elements while minimizing costs. The skills taught in steps 2 and 6, which focus on learning TQM tools/techniques, should have a significant impact on the development of an operational system. At this level the organization can transform resources or data inputs into the desired product, service, or outcome, and deliver value to its customers. It needs to specify how the organization will allocate its resources in order to support infrastructure and production. Also, quality records must be maintained to prove compliance to the standard.

\section{Demonstrations}

\section{ISO 9001:2015}

ISO 9001:2015 is the latest version of the ISO 9001 standard and was released in 2015 . The guidelines contained in this new revision are based on the 
results of an extensive survey, and consider the increasing diversity of ISO QMS users, new developments in knowledge and technologies, broader interest of users in matters related to quality, and changes in the industry. The revisions in this version include:

- Increased emphasis on achieving value for the organization and its customers.

- Increased flexibility in the use of documentation, making it more readily applicable to the "service" organizations instead of just focusing on a specific product.

- Elevated structure.

- Improved capability for services organizations.

- Fewer prescribed requirements.

- Increased emphasis on organizational context.

- Increased leadership requirements.

- Replacement of the term "documents and records" with "documented information".

- Replacement of the term "outsourcing" by "external provision".

- Replacement of the term "product" by "goods and services".

Notably, the 2015 version emphasizes risk-based thinking, which is explicitly built into the whole management system. Risk-based thinking can help identify opportunities that can be considered as the positive side of the risk. The adoption of this term could help improve customer confidence and satisfaction and assure consistency of quality goods and services. Overall, this new version intends to ensure a more satisfactory implementation and focuses not only on specific products but also services.

The ISO 9001:2015 standard is used in this research as the QMS for the proposed stepwise TQM implementation approach. The approach is described below.

\section{Case descriptions and demonstrations}

Company $\mathrm{A}$ is used as an example to demonstrate the approach proposed in this study. Company A is a company that manufactures construction equipment. Although the company expresses confidence in many areas its clients insist that they obtain an ISO 9001 certification. These calls intensify after the release of the latest version of the ISO 9001 standard, and the company is requested by their clients to upgrade the QMS. When starting this upgrade project the management team decides to employ the stepwise approach proposed in this study to gain more benefits throughout the company from the implementation of TQM.

Step-1: Building faith in the TQM approach using the historical examples of role models/ organizations/enterprises.
In this case, Company A decides to focus on Deming's studies. The CEO of Company A decides to start building the employees' faith in TQM by reading from Deming's most inspirational book, "Out of Crisis", to motivate their employees. The CEO then creates weekly study groups in each department within the organization. He proposes that each employee should read this book within four weeks. At the weekly study group discussions, all the employees are together and discuss their discoveries, experiences, and how they can apply the new acquired knowledge within the organization.

The purpose of this method is to make all the employees feel like they are a part of the organization's product or service development. This exercise can help the employee feel comfortable to approach the CEO with new ideas, concerns, or even complaints, hopefully establishing a stronger relationship among the employees, managers, and even the CEO.

Step-2: TQM tools/techniques learning-1: Learning about TQM tools and techniques using the educational tools/techniques relating to quality.

In order to help the employees to work in a smarter and more effective manner Company A decides to help them learn the seven quality tools. The tools are fundamental instruments that help improve product quality. They are a fixed set of graphical techniques identified as being most helpful in problem-solving. They are suitable for people with little formal training in statistics, and thus, they can be used to solve the majority of quality-related issues.

The three-month training program covers the description of the tools, when to use them, procedures to apply the tools, how to interpret the results, as well as examples of previous applications and exercises to support the learning. Company A encourages its employees to continue their education and also supports their professional development.

Step-3: TQM faith building-2: Building faith in the TQM approach using the current examples of role models/organizations/enterprises.

After finishing the reading of Deming's book, Company A decides to adopt Jack Welch as their second role model. Jack Welch took over GE's operations in 1981, becoming the youngest CEO in GE's history. The legendary leader made a resolution to transform GE into the world's most competitive enterprise. Welch, who is a strategic thinker, business teacher, corporate icon, and management theorist, devised 12 lessons which when implemented contributed to the largest corporate makeover in history. By studying the 12 lessons Company A hopes to achieve success, just like Jack Welch did for GE. 
The 12 lessons are "Lead, not manage", "Get less forma"1, "Don't tolerate bureaucracy, blow it up", "Face reality, stop assuming"... etc. To understand these lessons more thoroughly, Company A establishes a study group to discuss each lesson individually, and it conducts a workshop where groups of employees implement these lessons and analyze the best way to interpret them for the rest of the employees through their leadership. The workshop serves to understand the outcomes related to future products and services, and teaches employees the need to be more sociably responsible.

Step-4: ISO system developing-1: Developing an ISO-based system at the strategic level.

The ISO standard is mainly concerned with continuous improvement in all activities, from high-level strategic planning and decision making to detailed execution at the strategic level.

The latest version of ISO 9001:2015 contains the following 10 clauses. 1. Scope, 2. Normative References, 3. Terms and Definitions, 4. Context of the Organization, 5. Leadership, 6. Planning, 7. Support, 8. Operation, 9. Performance Evaluation, and 10. Improvement.

Certain clauses in this new version, namely, 1,3 , 4, 5, and 6, are more adaptable to the development of a TQM system at the strategic level. The remaining clauses will be explored in step-8. These clauses involve close interactions among people, encouraging the creation of a suitable strategy within the given working environment. Thus, employees are vital for the system to function as intended. These clauses are explained below in some detail.

- Clause 1 - Scope: To assess the requirements of Company A, and to understand how it will deliver the product to meet the customers' requirements through the effective application of the system.

- Clause 3 - Terms and Definitions: To establish all the terms and definitions that are necessary for the employee to know within the context of the organization; since Company A manufactures construction equipment, it would be prudent for the company to define all the materials it uses so the employee does not mistreat them or handle them irresponsibly.

- Clause 4 - Context of the organization: To understand the organization, from the context of the processes involved in manufacturing the product/delivering the service; Company A would have to establish the processes used during product manufacture, from beginning to end, as well as the procedure to be followed once product manufacture is complete.

- Clause 5 - Leadership: To demonstrate leadership while developing the TQM system; this is be- cause not only do all the parties have to be willing to commit to the changes that will follow, but they should continue to do so until the very end of the implementation. Thus, the company must have a guide throughout the whole process so as to not circumvent any steps.

- Clause 6 - Planning: To plan the solutions to potential risks and opportunities that can help the organization meet all its requirements toward delivering a quality product/service; Company A utilizes many pieces of equipment (small and big machinery), so planning solutions to potential risks would not only be safe but also effective in the case of a mishap whether is in the process or documentation matter.

Using the ISO-based system approach along with the faith built in TQM via steps 1 and 3 will help achieve and sustain high quality performance comprehensively and effectively across the entire organization. For example, the executive team members in Company A learned much from Edwards Deming and Jack Welch in steps 1 and 3, and thus, they are able to develop important ideas with regard to organizational value and leadership, or hire a consultant to help them implement these ideas.

Step-5: TQM faith building-3: Building faith in TQM with the help of role models within the organization.

Company A has completed its study of role models or quality gurus such as Deming and Welch. The employees decide to choose the production manager of the organization as their role model because he has good knowledge about these two personalities, shows a high interest in implementing their strategies, and aspires to achieve good quality products/services.

It is important to recognize good role models within the organization, particularly when considering their achievements in TQM implementation. Such role models are typically employees that have a positive attitude toward work, their responsibilities, co-workers, and customers. Such role models can help to provide a vision to make the other employees feel actively involved in the organization's goals. It is preferable to have role models that have received public awards, as it demonstrates his/her superior performance and ability to be more fair and flexible in dealing with employees because of his/her experience. Thus, a role model from within the organization can help encourage the professional growth of co-workers and others.

Step-6: TQM tools/techniques learning-2: Learning about TQM tools and techniques by implementing quality improvement projects.

In order to learn about TQM tools and techniques, the employees need to practice them. Learn- 
ing how to work these tools will help clarify the concept of TQM.

In order to make the learning experience more interesting and keep the employees motivated, Company A decides to hold a contest among its employees to see who devises the best idea for quality improvement or product/service innovations. This contest is to be held every six months, and employees can even compete for a national award for best performance in quality improvement projects. This can not only motivate the employees to opt for a better working position but also assure them that their efforts are not in vain and are appreciated.

Step-7: TQM faith building-4: Building faith in TQM by devising quality improvement projects.

After having implemented all the previous steps, it should be easier for the employees to enhance their faith in TQM.

Company A then decides to set up an incentive system to promote employees who practice TQM. It is found that performance is significantly enhanced when employees are involved in TQM implementation since the beginning of its inception, which, in turn, enhances their confidence via implementation. If the employees are involved in all the activities of the new incentive system from the outset they gain knowledge of this system and become familiar with its working and effects, and therefore, are prepared for the changes that accompany a new system. If the organization builds such faith from the time the approach is first adopted, it can even encourage employees to enhance their productivity. They can pass on their newly acquired knowledge to their subordinates and maintain a good relationship with their colleagues.

By this stage of the process, an employee should have become character-driven, reliable, and positive by exceeding expectations and willingly taking on any task assigned to him/her.

Step-8: ISO system developing-2: Developing an ISO-based system at the operational level.

To develop an ISO system at an operational level, Company A analyzes the results, compares them against the set goals at the strategic level, and defines the system using the remaining clauses.

- Clause 7 on "support" refers to the provision of resources needed for the maintenance of the TQM system. Company A needs to ensure that it can meet its customers' requirements in a timely and effective manner by providing support to the employees responsible for the operation of the QMS, which includes all the processes performed for the manufacture of the construction equipment.
- Clause 8 on "operation" refers to the plan that needs to be prepared depending on the customers' requirements. The requirements will define the actions needed to support the objectives, namely the delivery of a quality product/service. According to this clause, Company A needs to establish procedures necessary to communicate with their customers. The procedures should contain all the information relating to its products/services, be it contracts, enquiries, or equipment handling.

- Clause 9 refers to "performance and evaluation". The company needs to measure the expected performance of an employee, his/her development needs, and outcomes to assess whether employees' achievements are above or below the expectations of the organization. Company A can monitor customer satisfaction in any way it finds feasible. This will help the company to enhance customer satisfaction, demonstrate conformity of the equipment with customer requirements, and determine how and where they might be able to improve.

- Clause 10 refers to "improvement". Here, Company A determines and selects opportunities to enhance growth or implement necessary actions to fulfill all the requirements of its customers, the final goal being to deliver a top quality product (in this case, construction equipment).

The documentation needed to fulfill the requirements of this clause includes the organizational structure, responsibilities of employee, and required actions. In order to define subsystems clearly, activities in each area must be documented and reviewed to ensure that all the requirements are fully met, and most importantly, to identify any problem areas and rectify them by using all the necessary corrective and preventive measures. Thereafter, the employees should be trained to ensure that they are capable of carrying out their job functions.

Step-9: TQM faith building-5: Building faith in TQM by "self-actualizing" quality improvement projects.

After implementing the previous steps, the organization starts enjoying many benefits. This process has thus become an important management tool, providing step-by-step instructions to ease implementation, and help increase productivity by allowing the employee to self-actualize and fulfill their career development goals. In doing so, employees also achieve their goals with regard to the organization. Initiating and participating in quality improvement projects often allows achieving incremental and measurable changes which makes an actual difference and help the employees to think differently rather than just use the traditional approaches. 
Here, it is prudent for Company A to measure the satisfaction level amongst their employees. Surveys are conducted every six months to make sure that the employees are satisfied with their jobs and implementing the new rules.

\section{Discussion and conclusion}

To ease TQM implementation, the approach should be applied as proposed in this paper, namely, in a stepwise manner, in terms of the three components: 1. faith building, 2. learning tools/techniques, and 3. system development. We believe that grasping the notions behind these definitions will help organizations to understand and implement TQM. The first task is to emphasize the importance of faith building. The next task is to identify adequate tools and techniques depending on the organization's requirements or the product/service to be delivered. The last task is to develop an appropriate system that can support the organization's previous as well as new methods. This study, therefore, can act as a guide to companies that wish to implement TQM in an easier manner. The proposed approach is outlined below.

First, the organization begins with building employees' faith in the TQM approach. Second, it imparts training to its employees with regard to TQM tools and techniques, and last, the organization develops an appropriate ISO-based system to help it implement TQM.

We focus on building faith in TQM because we consider it to be the most important aspect with regard to establishing a better defined organizational culture which should benefit not only the organization but also its employees' personal growth. This aspect is important because, currently, organizations tend to focus only on implementing an ISO-type of TQM system; they do not perceive the importance of building the foundation before beginning implementation; in other words, it is crucial to align the thoughts of all its employees along the same lines.

Dahlgaard-Park et al. [6] stated that TQM has reached a point where it needs to be explored further. They believed that the focus of TQM has shifted from quality tools and techniques to core values, which are a must to implement TQM correctly and build an appropriate quality culture. This approach serves as a "back to basics" exercise in the sense that the organization needs to take the time to refocus its attention on the fundamental business elements and practices that tend to be neglected before the implementation of TQM.

On the other hand, the proposed approach can help an organization solve the conflicts between the implementation of an ISO system and the TQM approach. Tsim et al. [14] found that implementing ISO 9001 could lead to loss of flexibility as its rigid documentation requirements may hamper the organization's ability to make quick changes.

Most surveyed ISO-certified organizations respond that the system provides no benefits once ISO 9001 certification is complete. In order to survive and prosper in a highly competitive business environment, it is not enough to implement a QMS based on the ISO 9001 standard only even if it is aimed at achieving customer satisfaction by preventing product/service nonconformities. Instead, a more proactive QMS driven by customer satisfaction and rapid response to market environments is a necessity.

The approach proposed in this study can benefit any organization as it focuses on the strategy of maintaining not only the ISO certification even after the three-year certification period is complete but also working to fulfill a clear business objective, namely planning, managing, and delivering the final product or service. The proposed approach can also help resolve the rigidity prevalent in implementing the ISO standard by moderating the process using the proposed steps. Additionally, since TQM implementation follows no concise methodology, the proposed stepwise implementation makes it easier for the organization to communicate its plans, objectives, and strategies to all its employees.

\section{References}

[1] Dahlgaard J.J., Chen C.-K., Jang J.-Y., Banegas L.A., Dahlgaard-Park S.M., Business excellence models: Limitations, reflections and further development, Total Quality Management \& Business Excellence, 24, 519-38, 2013.

[2] Dotchin J.A., Oakland J.S., Theories and concepts in Total Quality Management, Total Quality Management, 3, 133-145, 1992.

[3] Hellsten U., Klefsjö B., TQM as a management system consisting of values, techniques and tools, The TQM Magazine, 12, 238-44, 2000.

[4] Quazi H.A., Hong C.W., Meng C.T., Impact of ISO 9000 certification on quality management practices: a comparative study, Total Quality Management, 13, 53-67, 2002.

[5] Black S.E., Lynch L.M., Human-capital investments and productivity, The American Economic Review, 82, 263-67, 1996.

[6] Dahlgaard-Park S.M., Chen C.-K., Jang J.-Y., Dahlgaard J.J., Diagnosing and prognosticating the quality movement - a review on the 25 years quality 
literature (1987-2011), Total Quality Management \& Business Excellence, 24, 1-18, 2013.

[7] Dahlgaard-Park S.M., The quality movement: where are you going, Total Quality Management \& Business Excellence, 22, 493-516, 2011.

[8] Porter L.J., Tanner S.J., Assessing Business Excellence (2nd ed.), Elsevier Butterworth-Heinemann, Linacre House, Jordan Hill, Oxford, 2004.

[9] Sun H.G., Diffusion and contribution of Total Quality Management: an empirical study in Norway, Total Quality Management, 10, 901-914, 1999.

[10] Gharakhani D., Rahmati H., Farrokhi M.R., Farahmandian A., Total Quality Management and Organizational Performance, American Journal of Industrial Engineering, 1, 46-50, 2013.

[11] Dahlgaard-Park S.M., The evolution patterns of quality management: some reflections on the quality movement, Total Quality Management, 10, 473-80, 1999.

[12] Poksinska B., Dahlgaard J.J., Antoni M., The state of ISO 9000 certification: a study of Swedish organizations, The TQM Magazine, 14, 297-306, 2002.

[13] Boulter L., Bendell T., Dahlgaard J., Total quality beyond North America: a comparative analysis of the performance of European Excellence Award winners, International Journal of Operations \& Production Management, 33, 2, 197-215, 2013.

[14] Tsim Y., Yeung V., Leung E.T., An adaptation to ISO 9001: 2000 for certified organisations, Managerial Auditing Journal, 17, 245-50, 2002.

[15] Hendricks K., Singhal V., Does implementing an effective TQM program actually improve operating performance? Empirical evidence from firms that have won quality awards, Management Science, 43, 9, 1258-74, 1997. 